\title{
Ocular findings in a case of fucosidosis
}

\author{
MARJORY B. SNODGRASS \\ From the Stirling Royal Infirmary, Scotland
}

In fucosidosis an inborn error of metabolism causes a deficiency of $\alpha$-L-fucosidase. The clinical picture was first identified by Durand, Borrone, and Della Cella (r966) and the biochemical abnormalities first described by Van Hoof and Hers (1968). Fourteen cases have so far been reported. The inheritance of the condition is autosomal recessive in type. In some cases relatives have been shown to be carriers of the defect with a level of $\alpha$-L-fucosidase midway between normal and that found in the established disease.

Fucosidosis presents gross neurovisceral disorders and there are two clinical groups. In the first there is severe progressive cerebral degeneration with gradual muscle loss and spasticity leading to decerebrate rigidity and death in the first few years of life. In the second group the signs appear later and deterioration is slower. In addition to neurovisceral changes there may be gross skeletal abnormalities. Some cases in the second group have a generalized skin lesion which develops slowly and resembles the angiokeratoma corporis diffusum of Anderson-Fabry disease (Wallace, 1973), but it differs in that the characteristic glycolipid material is absent and also the $\alpha$-galactosidase level in leucocytes and fibroblasts is normal.

The ocular findings in fucosidosis have not been described in detail. Gatti, Borrone, Trias, and Durand (1973) reported 'slight cloudiness of corneae' in some cases. Borrone, Gatti, Triad, and Durand (I974) reported 'strabismus' with 'papilloedema with congestion and tortuosity of retinal vessels' in one case and 'thin and tortuous vessels' in an affected sibling ( $\mathrm{Ng}$, Donnell, and Kock, 1973).

\section{Case report}

The case was the first to be recorded in the UK. Primrose (1972) reported the clinical details and MacPhie, Logan, and Primrose (1975) the diagnostic biochemical finding of absence of $\alpha$-L-fucosidase. The patient, a 24-year-old Caucasian woman, was an only child. Her mother was dead and her father was unknown. Her maternal grandfather was himself the only surviving

Address for reprints: Dr M. Snodgrass, Stirling Royal Infirmary, Stirling, Scotland child of a first-cousin marriage. She is now severely mentally retarded. She sees well enough to recognize people, hears normally, and is able to say an occasional word. Neurological degeneration is progressive with resulting flexion contractures of legs and arms. Her features are coarse, resembling gargoylism (Fig. I), and her skull is large (circumference $56 \mathrm{~cm}$, length $18.5 \mathrm{~cm}$, breadth $15 \mathrm{~cm}$, cephalic index 0.81 ). Her tongue is also large and coarsely fissured, her neck is short, and she has pronounced dorsal scoliosis. Her hands and fingers are long and straight. Positive $x$-ray findings include prognathism, deformities of ribs, scoliosis with partial fusion of lower thoracic vertebrae, and gibbous deformity of lumbar vertebrae. In the wrists scaphoid, trapezium, and trapezoid bones are absent (Fig. 2). The most striking feature is a generalized skin condition (Fig. 3) consisting of red to dark red macules and papules, especially on the breasts, thighs, and pelvic area. Blood can be expressed from some but not others, which appear papillomatous-especially in flexural areas. Histologically they are reported to be 'simple lymphangiomas with a marked angiomatous element'.

The eyelids have an antimongoloid slant. The distance between the inner canthi is $35 \mathrm{~mm}$ and between the outer $102 \mathrm{~mm}$. There is an alternating concomitant divergent strabismus $\left(-15^{\circ}\right.$ to $\left.-20^{\circ}\right)$. With eyes fixing centrally in alternation, the interpupillary distance is 73 to $74 \mathrm{~mm}$. There are small red macules and spider naevi on the lids and brow which empty on pressure.

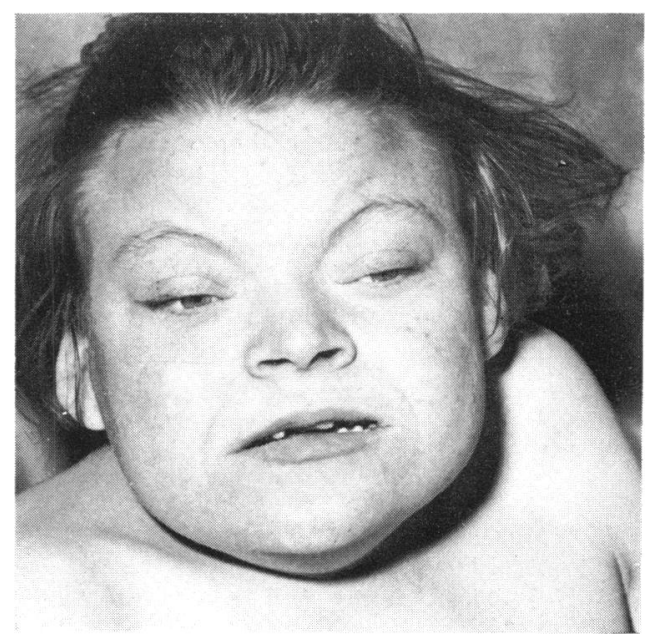

FIG. I Coarse features resembling gargoylism 


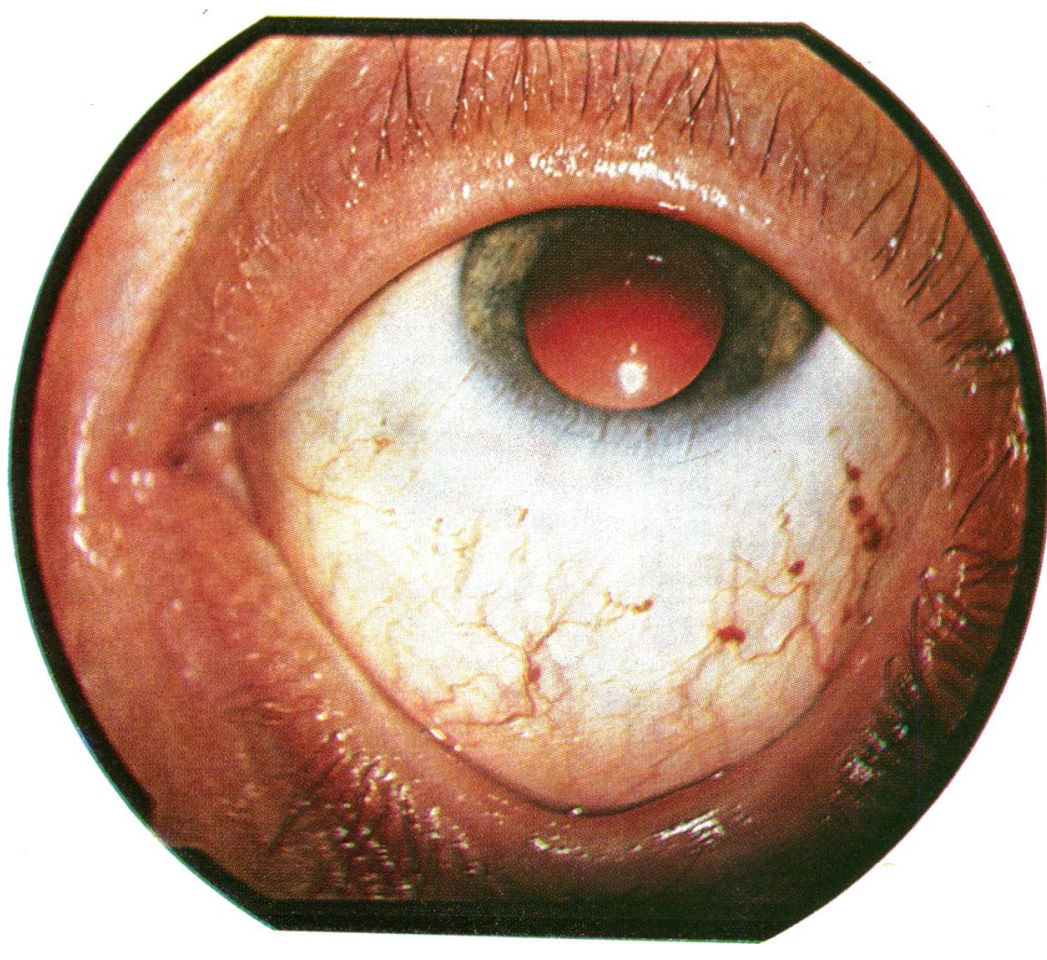

FIG. 4 Dilated, tortuous conjunctival vessels, some with saccular dilatations

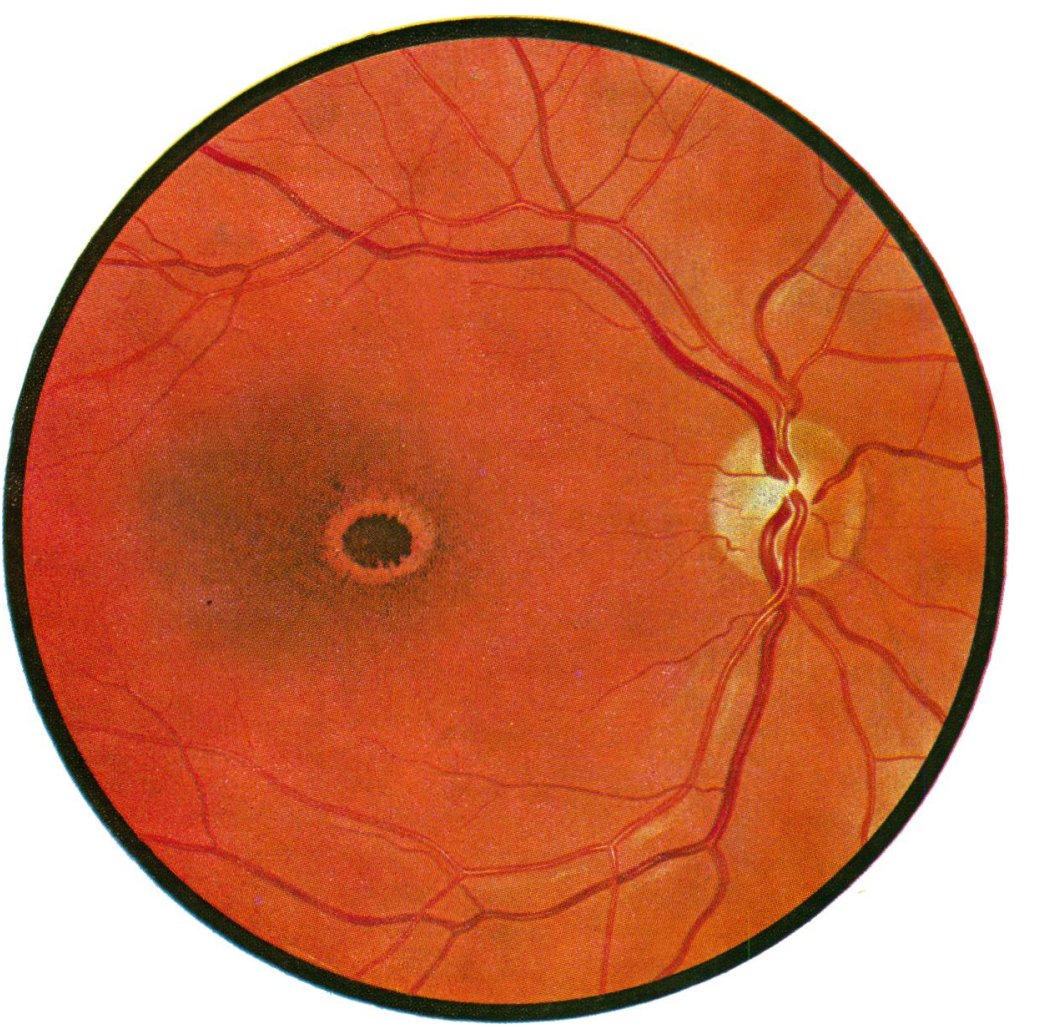

FIG. 5 Fundus of left eye (painted from description given by author) 


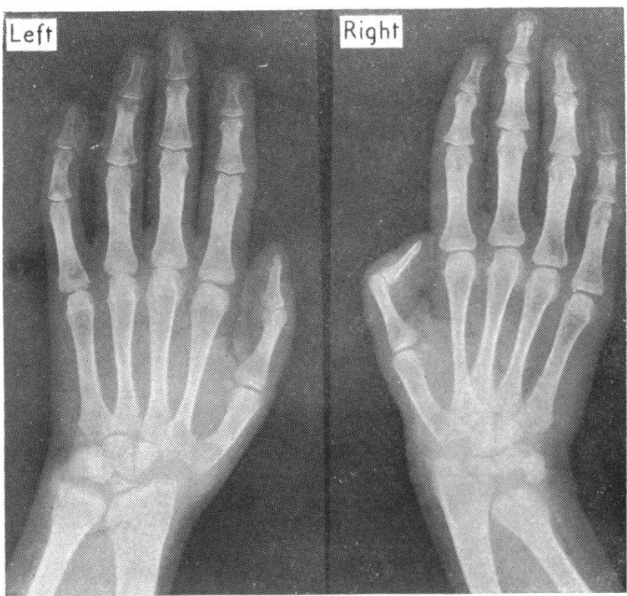

FIG. $2 X$-ray films of hands and wrists: absence of scaphoid, trapezium, and trapezoid bones

Blepharospasm is frequent. Both bulbar and, to a lesser extent, palpebral conjunctivae, have dilated tortuous vessels, some with saccular dilatations (Fig. 4). There is a moderate hypermetropic astigmatism with the rule. The corneae are oval transversely (estimated vertical diameter $10 \mathrm{~mm}$, horizontal $12 \mathrm{~mm}$ ) due to some scleralization at the limbus above. The anterior chambers are of normal depth and the corneae and lenses are clear. The fundi show macular changes resembling bull's eye retinopathy. The foveal area has fine brown pigmentation and is ringed by a zone of hypopigmentation. The rest of the macular area has fine brownish, slatey-blue pigmentary change with occasional clumps of dark brown pigmentation. The discs and vessels are healthy and there is no undue tortuosity of the vessels. In the equatorial region in the left eye near the inferior temporal vessels are two small brown pigmented spots surrounded by an areola of hypopigmentation (Fig. 5).

The patient's maternal grandfather, the only relative able to be examined, is physically and mentally normal and his fundi are healthy. His $\alpha$-L-fucosidase level is about half of normal.

\section{Discussion}

Unfortunately, because of the patient's almost complete inability to co-operate and her blepharospasm, special examinations could not be performed. The general appearance and $x$-ray changes in ribs, spine, and wrists are similar to those found in gargoylism. However, she has no other clinical features or diagnostic enzymatic deficiencies to support a diagnosis of mucopolysaccharidosis.

The widespread maculo-papular rash and the saccular dilatations in the conjunctival vessels resemble those described by Velzeboer and de Groot (I97I) in Anderson-Fabry disease. This diagnosis can be excluded by the absence of the characteristic histology and the presence of a normal $\alpha$-galactosidase level. The fundal changes of bull's eye maculopathy resemble those first

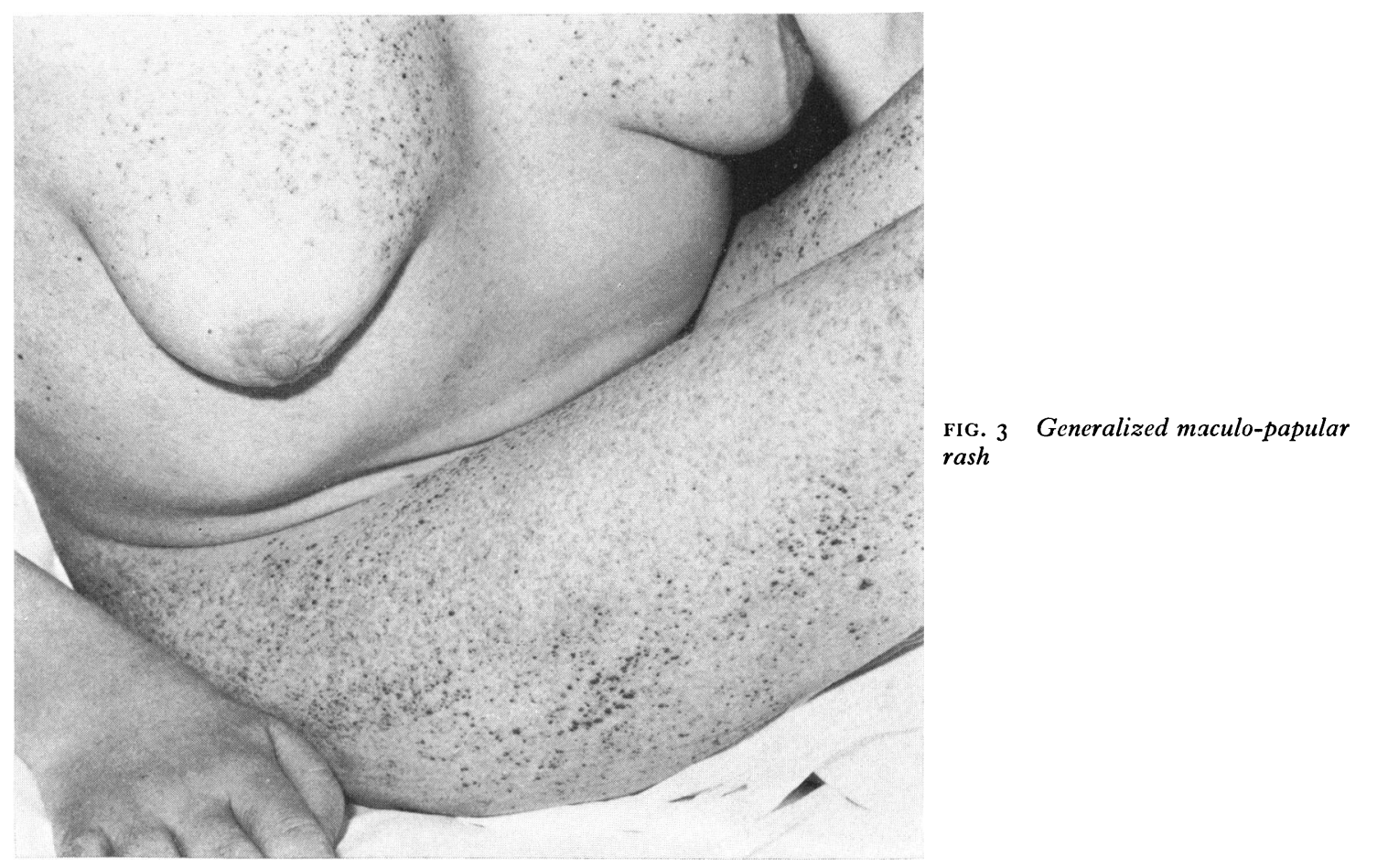


described by Hobbs, Sorsby, and Freedman (1959) in cases of chloroquine poisoning. Recently a similar clinical picture has been noted by Weise and Vannuzzi (1974) in nine patients in the absence of chloroquine therapy. This maculopathy has also been reported in children in a hereditary form by Deutman (1974). After extensive investigations he showed it to be due to degeneration of cones. Neither of these two groups of bull's eye maculopathy shows any clinical features of fucosidosis, but could there be a relative deficiency of the enzyme as a predisposing factor?

\section{Summary}

The ocular findings in a case of fucosidosis are described and the differential diagnosis is discussed. It is suggested that the level of $\alpha$-L-fucosidase should be estimated in cases of bull's eye retinopathy.

I thank Dr J. Dudgeon, Department of Ophthalmology, University of Glasgow, for his helpful advice, and Mr G. Donald, Director of Medical Illustration, Glasgow Western Infirmary, for his fundus painting. The Carnegie Trust is thanked for assistance in the reproduction of the colour illustrations.

\section{References}

Borrone, G., gatti, R., triad, c., and DURAND, P. (1974) F. Pediat., 84, 727

DeUtMan, A. (1974) Trans. ophthal. Soc. U.K., 94, 643

DURAND, P., BORRONE, C., and DELLA CELla, G. (1966) Lancet, 2, I3I3

GATTI, R., BORRONE, C., TRIAS, X., and DURAND, P. (I973) Ibid., 2, 1024

HOBBS, H. E., SORSBY, A., and FREEDMAN, A. (1959) Ibid., 2, 478

MACPHIE, G. B., LOGAN, R. W., and PRIMROSE, D. A. (1975) Ibid., 2, 462

NG, W. G., DonNell, G. N., and коск, K. (1973) Pediat. Res., 7, 163, 391

PRIMROSE, D. A. (1972) f. ment. Defic. Res., 16, 196

VAN HOOF, F., and HERS, H. G. (I968) Lancet, I, I I 98

vELZEBOER, c. M. J., and DE GROOT, w. P. (1971) Brit. F. Ophthal., 55, 683

wallace, H. J. (I973) Brit. F. Derm., 88, I

weise, E. E., and vannuzzi, L. A. (1974) Amer. F. Ophthal., 78, 204 